\title{
A Metrópole Comunicacional 3.0
}

\author{
Communicational Metropolis 3.0
}

Fabricio Farias Tarouco* Gabriel Gallina Jorge **

*Doutor em Comunicação e Mestre em Design Estratégico, pela Universidade do Vale do Rio dos Sinos (UNISINOS, RS). Realizou Estudos Avançados em Lenguajes y Sistemas Informativos na Universidad de Zaragoza, Espanha. Graduado em Design Gráfico pela Universidade Federal de Pelotas (RS) e em Análise de Sistemas pela Universidade Católica de Pelotas (RS). Atua como Professor e Coordenador do Bacharelado em Design e também é pesquisador nos Programas de Pós-Graduação de Design e de Arquitetura e Urbanismo da UNISINOS.
** Mestre em Design Estratégico (UNISINOS, RS). Especialista em Marketing pela Fundação Getúlio Vargas e Graduado em Arquitetura e Urbanismo pela Universidade Luterana do Brasil (ULBRA). Fo sócio fundador do Studio $\mathrm{Pa}$ ralelo, de 2001 a 2005, coor denador de projetos do GAD Design, de 2005 a 2008, e sócio fundador da SCENO Environmental Graphic Design, de 2009 a 2015. É professor de Arquitetura na ULBRA; e de Design Gráfico e Design de Interiores na Faculdade de Desenvolvimento do Rio Grande do Sul.

\section{Resumo}

O artigo apresenta, discute e atualiza o conceito de metrópole comunicacional proposto por Massimo Canevacci, fazendo uma reflexão sobre seus desdobramentos a partir de um olhar histórico e evolutivo. Ao revisar a trajetória progressiva deste conceito, o artigo acrescenta o processo de softwarização das práticas e experiências comunicacionais presente nas cidades, e conclui dialogando sobre a smartphonização das dinâmicas urbanas que vem emergindo no contexto explorado. Considerando a conexão de cidadãos e cidade através dos apps, o artigo apresenta uma nova metrópole comunicacional tensionada pela atualização constante dos recursos tecnológicos que a conduzem, dando origem a denominação Metrópole Comunicacional 3.0.

Palavras-chave: Cidades. Softwarização. Smartphonização.

\section{Abstract}

The article presents, discusses and updates the concept of communicational metropolis proposed by Massimo Canevacci, reflecting on its unfolding from a historical and evolutionary perspective. The article reviews the evolution of this concept, adding to it the process of softwarization of practices and communicational experiences present in the cities. It ends with a discussion about the smartphonization of the urban dynamics that has emerged in communicational metropolis. Considering the connection of citizens and cities through apps, the article presents a new communicational metropolis modified by the constant updating of the technological resources observed in this context. Therefore, the communicational metropolis is, then, understood as Communicational Metropolis 3.0 in this study.

Keywords: Cities. Softwarization. Smartphonization. 


\section{Introdução}

conceito atual de metrópole, interpretado por por Benevolo (2012), vem representar a forma mais conhecida de organização da sociedade contemporânea, na qual milhares de pessoas passaram a viver em centros urbanos integrados na expectativa de encontrar melhores condições de vida. Sua busca aspira desde oportunidades de emprego até mais produtos industrializados, bem como serviços de melhor qualidade, como saúde, transporte, cultura, e educação, entre outros. Foi o contínuo e acelerado crescimento de algumas cidades que ocasionou a formação das metrópoles atuais, que configuram-se como grandes aglomerados urbanos que passaram a servir de referência geográfica e comercial, tanto em nível regional como global. É neste cenário que Massimo Canevacci (1993) introduz o conceito de metrópole comunicacional, interpretado aqui com a primeira geração de um olhar sobre as cidades, e que nesta pesquisa será referenciada como a metrópole comunicacional 1.0. Este conceito faz referência a transição de uma cidade industrial para uma metrópole com multiplicidade de vozes autônomas que se cruzam, relacionam-se e sobrepõem-se harmonicamente umas às outras.

Para avançar no raciocínio, resgata-se Dubois (2004), que diz que as quatro últimas tecnologias que surgiram e introduziram uma dimensão de máquina com um caráter inovador no seu dispositivo foram a fotografia, o cinematógrafo, a televisão/vídeo e, por fim, a imagem informática. Observa-se que a última citada está presente em muitas superfícies contemporâneas, inclusive num dos dispositivos de comunicação mais populares da atualidade, os 'smartphones'. Estes representam a última geração de telefones celulares inteligentes com funcionalidades móveis avançadas e sistemas operacionais que permitem agregar milhares de programas adicionais (aplicativos), com diversas utilidades para seus usuários. Estes telefones se posicionam hoje como verdadeiros pontos de conexões móveis e contínuos, proporcionando mobilidade ao indivíduo que circula pelos espaços físicos, fazendo, conforme Santaella (2007), com que o sujeito que fala no telefone celular seja parte e ao mesmo tempo esteja mentalmente afastado, até certo ponto, do contexto 
daqueles que ocupam a mesma área espacial. Dados da Abinee ${ }^{1}$ (2013) estimam que, em pouco tempo, praticamente todos os aparelhos de telefonia móvel em uso serão smartphones, já que a comercialização de aparelhos tradicionais vem caindo pela metade, enquanto os smartphones apresentam crescimento anual de vendas superior a $100 \%$. Segundo levantamento feito pelo Ericsson ConsumerLab (2015), a venda de smartphones e tablets supera a de computadores tipo PC desde 2011. Devido a sua característica de portabilidade, tais aparelhos estão se tornando o principal dispositivo de acesso à internet e, por isso, viraram alvo da disputa de gigantes empresas da rede, como o Google, Facebook e Yahoo, entre outras.

É neste contexto de metrópole comunicacional receptora de interferências tecnológicas, que os dispositivos móveis de comunicação (os populares smartphones, tablets e seus similares) impõem novas dinâmicas de comunicação e convívio, sobretudo quando observamos um conjunto de aplicativos especialmente projetados com promessas de facilitar e intensificar essa relação entre usuário e seus territórios (lugares que vivem e frequentam). Trata-se aplicativos que se agregam à experiência digital no contexto das cidades, tensionando-a e transformando seus hábitos (de comunicação, convivência, localização e uso de serviços públicos e privados, entre outros) que se veem afetados e modificados a partir da introdução dessa tecnologia. A cidade vivida por meio destes aplicativos móveis pode representar uma terceira geração da metrópole comunicacional de Canevacci, interpretada neste artigo como a metrópole comunicacional 3.0.

Sendo assim, este artigo busca revisar o conceito de metrópole comunicacional visitando três momentos de sua evolução histórica, sendo: 1. a própria constituição deste entendimento de metrópole comunicacional; 2. o processo de softwarização das práticas e experiências comunicacionais nas cidades e, por fim, 3; a smartphonização das dinâmicas estabelecidas, que conecta os cidadãos ao espaço urbano em que vivem.

\section{Metrópole Comunicacional 1.0 - A metrópole de Canevacci}

A forma de organização da sociedade atual está intrinsecamente relacionada ao conceito contemporâneo de cidade, entendimento este que é tomado como ponto de partida para estabelecer as conexões e análises pretendidas. Essa estrutura integrada e mutante, que absorve pessoas, serviços, urbanidades, tecnologias múltiplas e simultâneas interações permite visualizar e compreender as principais transformações culturais que o mundo viveu e está vivendo. É justamente nesse espaço urbano que a vida acontece em toda a sua plenitude, desde as ações mais simples, como a utilização de um transporte público, até as mais complexas, como a construção de prédios arranha-céus em um período de tempo considerado recorde, se comparado a épocas anteriores.
1. Abinee $=$ Associação Brasileira da Indústria Elétrica e Eletrônica. 
Alguns autores, como Benevolo (2012) e Blumenfeld (1972), registram que a origem dos primeiros aglomerados urbanos se estabeleceu entre quinze e cinco mil anos atrás, dependendo das diversas definições existentes sobre o que define de forma permanente uma cidade como sendo um antigo agrupamento. Olhando para os dias atuais, com a proliferação dos aglomerados urbanos e o consequente crescimento das capitais, observamos o surgimento das super cidades, ou melhor, de grandes centros urbanos que se transformam em referências geográficas e comerciais, passando a receber a denominação de Metrópole. Este termo é empregado para designar as populosas cidades centrais de áreas urbanas formadas por cidades ligadas entre si fisicamente ou através de fluxos de pessoas e serviços ou que assumam importante posição (econômica, política, cultural, etc.) na rede urbana da qual fazem parte (Souza, 2005).

A vida nestas metrópoles acompanha o processo acelerado das transformações vivenciadas nas últimas décadas e, também, o dinamismo que essas transformações acontecem. São mudanças de paradigmas, mudanças culturais, socioeconômicas e principalmente tecnológicas, que implicam necessariamente uma readaptação do indivíduo em seu meio.

É nesse cenário que o conceito de Metrópole Comunicacional, introduzido por Canevacci (1993) em suas pesquisas sobre a comunicação urbana, ganha projeção no meio acadêmico. $\mathrm{O}$ autor data nos idos de
1970 o início da transição de cidade industrial para o que denomina de metrópole comunicacional, transição esta que teve origem na cidade industrial, que tinha como monumento central a fábrica, evoluindo à metrópole comunicacional da atualidade, muito mais estruturada sobre o consumo e sobre a comunicação. Essas pesquisas têm por base a antropologia urbana, uma antiga necessidade de conhecer o funcionamento da vida nas cidades para que se pudesse indiretamente controlar o processo de modernização e urbanização das mesmas, discussão essa iniciada quando as velhas potências coloniais passaram a estudar as cidades que iam se constituindo durante sua transição para a independência, nas ex-colônias.

Não se pode dizer que a dimensão industrial deixou de ser significativa nos dias de hoje, mas esse cruzamento entre comunicação e tecnologia digital favorece um tipo de transformação profunda na metrópole de anos atrás. Esta não mais está baseada numa relação entre o Estado e a Nação, mas sim passa a ser de grandes áreas metropolitanas e comunicacionais que competem e desenvolvem estilos que favorecem essa profunda transição. Para McLuhan (2005), a expansão da informação se tornou de longe a maior indústria do mundo, deixando de ser mecânica e se configurando num ambiente onde computadores e equipamentos eletrônicos movem a informação, que passa a ser produção também. Esta é uma época em que 'tudo se liga a tudo', seja pelo ar ou pelo cabo, constituindo verdadeiras cable-cities (cidades-cabos) que, além de reembaralhar o poder, são as primeiras a se transforma- 
2. O conceito de 'hipermetrópole' e 'megalópolis' são encontrados em Canevacci (1993), quando faz referências à cidade de São Paulo-SP por ter mais de dez milhões de habitantes.

3. 'O etnógrafo é um pouco como Hermes: um mensageiro que, contanto com algumas metodologias para descobrir o mascarado, o latente, o inconsciente, pode obter a sua mensagem até mesmo através do furto. Ele apresenta mensagens, culturas e sociedades em toda a sua opacidade, estranheza e falta de sentido; então, como se fosse um mágico, um hermeneuta - o próprio Hermes - esclarece o que não estava claro, torna familiar o que era estranho e dá sentido ao que era desprovido de sentido. Ele decodifica a mensagem. Ele interpreta.' (Canevacci, 1993) traduzido de (Crapanzano, 1986).

4. Foram 26 observações descritas no livro A Cidade Polifônica (CANEVACCI, 1993). rem de cidades-industriais em cidades-cultura, como expõe Featherstone (1992).

Próximo a tudo isso, Canevacci (1993) defende que as cidades em geral, e a comunicação urbana em particular, comparam-se a um coro que canta uma multiplicidade de vozes autônomas que se cruzam, se relacionam, sobrepõem-se umas às outras, isolam-se ou se contrastam, num simples fenômeno de 'dar voz a muitas vozes'. Dessa forma, a metrópole pode ser lida como um complexo sistema de práticas e um sofisticado universo imaginário inscrito nas suas superfícies, fachadas e construções. Hoje, as superfícies comunicacionais tomaram conta das metrópoles, deixando de ser exclusividade dos museus e invadindo as ruas e avenidas, sendo estáticas grudadas em antigas cabines telefônicas, em movimento como na lateral de um ônibus ou digital projetadas em grandes outodoors de led. É nesse cenário de cidade de incontáveis imagens, mensagens e superfícies urbanas que posiciona-se o entendimento de metrópole comunicacional. Todavia, outros conceitos relacionados por Canevacci (1993) mostram-se também fundamentais para compreender a metrópole difundida por ele, que tão frequentemente traz como referência suas experiências de turista na hipermetrópole ${ }^{2}$, de São Paulo, numa comparação a Roma, cidade onde tem residência.

Numa de suas pesquisas sobre comunicação urbana é resgatado o dilema de Hermes ${ }^{3}$, definido por Crapanzano (1986) como a arte de revelar o que está mascarado, utilizando para isso recursos de uma interpretação etnográfica. A intenção é descobrir o que é/ está desconhecido, mesmo que este desconhecido muitas vezes se esconda num excesso de familiaridade entre o que conhecemos e o que estamos observando. Para isso, Canevacci (1993) propõe uma contínua inversão metodológica, tornando familiar o que é estranho e estranho o que é familiar, num claro tensionamento entre os conceitos de estranhamento e familiarização. O objetivo de tal tensionamento é a decodificação das mensagens urbanas presentes na arquitetura, nas mídias, no comércio, na tecnologia e nas conexões ocasionadas entre estes e outros elementos. Esta decodificação das mensagens urbanas é definida como uma arte hermética e etnográfica, também denominada como arte de interpretar.

Todos estes conceitos e métodos são ilustrados por Canevacci (1993) em suas observações vivenciadas na cidade de São Paulo. Neste sentido, o autor aponta para o caso da rede de fast-food McDonald's que, segundo ele, recicla símbolos da religiosidade urbana presentes na arquitetura (da Idade Média) de uma das sedes de suas franquias, onde a marca de um $M$, grande, amarelo e profano, é colocada em destaque emitindo capacidades comunicativas para as multidões que o vê, convencendo-as a entrar sem mais complexos de culpa neste novo templo. Outro registro $^{4}$, narrado resgata hábitos antigos de passear vagarosamente em segurança pelas ruas de São Paulo, sem nada a perder exceto as horas, observando as vitrines de lojas e sendo procurado pelas mercadorias 
mais do que procurando-as, como nas passagens parisienses.

São esses fragmentos e essa pluralidade que constroem o entendimento de metrópole comunicacional e cidade polifônica difundido por Canevacci (1993), sendo estas configuradas pela copresença simultânea de fontes diversificadas e entrosadas, produzidas inicialmente pelo contexto urbano do início do século $X X$, que não mais observada com 'aquele conjunto complexo' unitário, mas, sim, como uma polifonia de subjetividades diversas representada na poesia, pintura, música, publicidade, moda, design, entre outras. O conceito de simultaneidade vem ampliar esse sistema cognitivo difundido num contexto comunicativo urbano, que vai mudando os sentidos das percepções numa direção polifônica e antecipa as duas principais categorias da Modernidade - a fragmentação e a justaposição. Os entendimentos de ubiquidade e permanência complementam esse olhar comunicacional sobre a metrópole, estando em muitos lugares, sem um centro único de comando ou irradiação, mostrando-se ao mesmo tempo contínuo, de duração constante.

\section{Metrópole Comunicacional 2.0 - A softwariza- ção das cidades}

Ao observar as transformações vividas na contemporaneidade, percebe-se que o advento do software representa uma nova camada sobreposta a paisagem da Metrópole Comunicacional, em que atua fazendo ver as vantagens e desvantagens do protagonismo das tecnologias e promovendo avanços e facilidades na rotina deste território. A sociedade moderna, em que o campo dos media ganha legitimidade, também é caracterizada como sociedade de informação, configurando uma era da evolução da humanidade ocasionada especialmente pelas recentes transformações tecnológicas nos domínios da eletrônica e das telecomunicações. Tais transformações resultam em uma verdadeira revolução da informação e seu acesso. Para Esteves (1998), a sociedade da informação promete não apenas a plena abundância, mas também a liberdade e a democracia nas suas formas mais perfeitas, sendo que o incremento da comunicação permite o aumento do conhecimento, da criatividade e da interação entre as pessoas. Ou seja, vive-se em uma época em que as tecnologias digitais proporcionam a todos seus usuários a possibilidade de amplo acesso à informação, além de muitos canais de expressão de opinião individual ou coletiva.

No olhar de Parente (1999), cada vez mais as telecomunicações condicionam os acontecimentos, as informações, os espaços e as pessoas, de forma que as articulações do veículo comunicacional vêm substituir a transparência do espaço de nossos percursos. O surgimento das tecnologias informáticas e midiáticas provocam novos processos de memorização e novas formas de comunicação, que caracterizam o mundo atual pelas fortes mudanças estruturais e pelo impacto que essas transformações 
promovem na sociedade. Essas mudanças indicam que se está vivendo mais um tempo muito especial da história humana, uma época de abertura, de evolução e de conquistas em termos de representação cultural, tal qual McLuhan já avistava quando pensava na TV, ou Benjamin percorrendo as metrópoles no século XIX.

A inserção das cidades na nova ordem digital é defendida por Martín Barbero ao expor que as cidades pós-industriais estão passando por transformações tecno-operativas importantes. Ao considerarmos a presença das novas tecnologias de comunicação, estas transformações se caracterizam por um movimento crescente de desterritorialização dos mundos simbólicos e esfacelamento de fronteiras entre o arcaico e o moderno, entre o local e o global, a cultura letrada e a audiovisual. Para Barbero (1996), entramos no paradigma informacional que atualiza o paradigma comunicacional, sendo esse o momento de desurbanização, fator que lida com a perda cada vez maior de uso da cidade pelos cidadãos. Isso significa que o fluxo pelas ruas, praças, avenidas e monumentos se fazem, agora, na lógica da necessidade e do trabalho, fazendo com que os cidadãos fujam do caos urbano, seja refugiando-se em espaços privados (shoppings, condomínios fechados e guetos), seja migrando para espaços virtuais e online.

Nesse sentindo, ao introduzir o conceito de Cibercidade, Parente (1999) apresenta uma visão de es- paço urbano construído a partir de dispositivos tecnológicos, propondo o repensar da relação entre os aspectos físicos e a representação desse espaço urbano. Para Smith (2007), o espaço digital pode assumir muitas formas, no entanto, em termos de cidade digital a preocupação é com a criação de um espaço que permita gerar uma compreensão visual da incorporação dos usuários ao ambiente digital.

Uma nova forma de vida e interação surge nesta cidade digital, considerada como não lugares por alguns autores por serem espaços virtuais que absorvem e transformam determinadas dinâmicas e fluxos, que até então aconteciam apenas nos ambientes reais, ou físicos propriamente. Nessa direção, Barbero (1996) afirma que na cidade dos fluxos comunicativos contam mais os processos que as coisas, a ubiquidade e instantaneidade da informação ou da decisão via telefone celular ou fax a partir do computador pessoal, a facilidade e rapidez dos pagamentos ou a aquisição de dinheiro pelos cartões.

Como já mencionado anteriormente, novos serviços digitais surgem em meio ao espaço urbano ou através de dispositivos tecnológicos, que dialogam digitalmente com esta metrópole comunicacional. Eles vão desde máquinas tecnológicas que interagem com a sociedade até equipamentos que conectam $o$ cidadão ao mundo e aos inúmeros e crescentes serviços disponibilizados de forma online. 
A denominada sociedade da informação, ou sociedade do conhecimento, ou ainda sociedade em rede, são concepções de uma era construída a partir de códigos, de algoritmos mais precisamente, e de softwares. É com base nesse contexto, em que os meios de comunicação se tornaram programáveis, que Manovich (2008) dá forma aos estudos do software, investigando tanto o papel do software na formação da cultura contemporânea quanto as forças culturais e sociais que moldam o próprio desenvolvimento desses códigos.

De acordo com o mesmo autor, hoje em dia os softwares administram estoques e linhas de produção, permitindo que as lojas e os supermercados reabasteçam automaticamente suas prateleiras, assim como também determinam automaticamente quais produtos devem entrar em oferta. Software é o que organiza a internet, encaminha mensagens de e-mail, encontra as páginas da web em um servidor, dirige $\mathrm{o}$ tráfego na rede, atribui os endereços de IP (Internet Protocol) e apresenta as páginas da web em um browser (navegador). A escola e o hospital, a base militar e o laboratório científico, o aeroporto e a cidade, bem como todos os sistemas sociais, econômicos e culturais da sociedade moderna, são atualmente acionados e gerenciados via softwares. Portanto, deve-se pensar o software como um componente cada vez mais presente e fundamental nesta sociedade, ainda que, muitas vezes, se apresente de forma paradoxalmente invisível em nossas relações. Manovich (2008, p.21) vai além em suas considera- ções, afirmando que:

Enquanto vários sistemas da sociedade moderna falam línguas diferentes e têm objetivos diferentes, todos compartilham as sintaxes do software [...]. Se a eletricidade e o motor a combustão tornaram possível a sociedade industrial, similarmente o software permite a sociedade da informação global. Os 'trabalhadores do conhecimento', os 'analistas de símbolos', as 'indústrias criativas' e as 'indústrias de serviços' - todos esses agentes vitais da sociedade da informação não podem existir sem o software. [...] 'Sociedade da informação', 'sociedade do conhecimento', 'sociedades em redes', 'mídia social' - não importa qual nova característica da existência contemporânea examinada por uma determinada teoria social, todas essas novas características são possibilitadas pelos softwares.

Nesse entendimento, o software é parte da cidade, e, se está presente na cidade, ele participa integralmente das dinâmicas da Metrópole Comunicacional. A expansão - e popularização - das tecnologias trouxe consigo mudanças significativas para a sociedade moderna. Ilustrando isso, recorda-se a experiência de passar longas horas em filas intermináveis em um banco. Esta situação mudou quando estas organizações passaram a migrar para sistemas online de gerenciamento de contas bancárias (internet banking). Se o dinheiro em papel está desaparecendo de circulação e sendo substituido pelo uso de cartões de crédito e débito, aliando inclusive facilidade e segurança às transações financeiras, é possível dizer que todo um contexto foi modificado 
5. TRI - Transporte Coletivo Integrado da cidade de Porto Alegre/ RS. Acessar www.tripoa.com.br pelo incremento tecnológico. Neste ponto, observamos que o fim das filas não foi apenas para os bancos, hoje é possível comprar ingressos para espetáculos musicais, cinemas e teatros sem precisar deslocar-se antecipadamente para estes locais. Situação semelhante vem também acontecendo com o cadastramento e procura por empregos, onde o antigo jornal de classificados vem sendo substituído por ofertas compartilhadas por recursos virtuais como e-mails, listas e redes sociais especializadas, como a plataforma LinkedIn.

Situações semelhantes em domínios diversos também vem sendo percebidas. O trânsito das cidades passou a ser orquestrado através dos recursos tecnológicos, em que sistemas de semáforos inteligentes e câmeras de gerenciamento de trânsito são determinados pela observação do fluxo de carros nas vias. Somam-se a isso controladores de velocidades e radares eletrônicos, que monitoram e aplicam penas aos infratores que excederem os limites de velocidade. A integração também chegou aos transportes públicos, com cartões magnéticos (como o sistema TRI ${ }^{5}$ ) que permitem o armazenamento de créditos para pagar as viagens, além da possibilidade de utilização de diferentes modais em um único bilhete. As paradas de ônibus passam a contar com serviços inteligentes de sinalização e informação, indicando ao usuário em quantos minutos chegará sua condução.

Na área da saúde surgiram serviços integrados de agendamento de consulta, diagnósticos comparti-
Ihados, central de reserva de leitos, exames com maior precisão e acesso online de resultados de análises clínicas. No ensino, a distância foi superada pelo surgimento de sistemas de educação a distância (EaD), que permitem a todos a possibilidade de qualificação contínua por acesso remoto e com investimentos menores.

Na área de habitação, destacam-se os sensores inteligentes de portas, luz, presença, alarmes de segurança, assim como os sensores antifurtos instalados na maioria dos empreendimentos comerciais. Nessa área da segurança percebe-se as câmeras de monitoramento e os sistemas integrados de banco de dados, assim como os serviços de rastreamento de carros.

Como se constata, são muitas as transformações que a introdução dos softwares ocasiona no cotidiano das cidades. Cita-se ainda o fim anunciado dos populares 'orelhões' (cabines telefônicas públicas) em virtude da proliferação dos dispositivos de telefonia móvel, bem como a perda de importância dos mapas impressos nas antigas listas telefônicas, tendo sua função substituída por plataformas como o Google Maps e/ou recursos similares. Os sistemas de geolocalização entram com força em um crescente número de serviços disponibilizados nos espaços urbanos, da mesma forma que o consumo, como era conhecido, vem sendo radicalmente transformado e desterritorializado, hoje é possível comprar praticamente tudo, em qualquer lugar, a 
qualquer momento e de qualquer procedência, de forma individual ou coletiva.

\section{METRÓPOLE COMUNICACIONAL 3.0 - A UR- BANIDADE EM APPS}

Nesse cenário de tecnologias em ascensão, as práticas comunicacionais e os processos midiáticos ganharam um impulso extra com o avanço e a proliferação dos dispositivos móveis de comunicação, que evoluem com grande velocidade e ganham qualidade, performance, múltiplas funcionalidades e cada vez maior abrangência de atuação. Segundo Pellanda (2011), o impacto deste tema transcende as questões comerciais e técnicas, visto que o acesso móvel à informação está se tornando a principal fonte de difusão do ciberespaço. Hoje em dia a quase totalidade de serviços disponibilizados nestes dispositivos se configura também em formato de aplicativos móveis - os apps que, em aproximadamente duas décadas, se popularizaram como um novo segmento de mercado virtual. Este mercado vem atingindo números cada vez mais expressivos, tanto de downloads como de recursos movimentados.

É fato que a relação entre o espaço urbano e as práticas comunicacionais passam por transformações importantes no atual momento da sociedade da informação, pois, segundo Lemos (2007), as tecnologias sem fio estão transformando as relações entre pessoas, espaços urbanos e criando formas alternativas de mobilidade. Para o autor, as mídias reconfiguram os espaços urbanos, dos subúrbios aos centros, dinamizando questões como

o transporte público e tornando mais complexo esse organismo-rede que são as cidades.

Para Walravens (2015), 2008 foi um ano marcante no contexto das cidades, vista a expressiva mudança estrutural que começava a se desenhar diante da consolidação das tecnologias móveis. Segundo este autor, três pontos merecem destaque: (1) foi neste ano que, pela primeira vez, houve mais assinaturas de banda larga móvel do que fixa; (2) constatou-se que haviam mais 'coisas' do que pessoas conectadas na internet; e (3) mais da metade da população mundial já vivia em cidades. Walravens (2015, p.282) observa que o primeiro ponto mostra a crescente importância da conectividade móvel, pois

À medida que os preços dos smartphones diminuem e as suas capacidades para gerar softwares mais avançados aumentam, os consumidores dependem cada vez mais desses dispositivos quando viajam em suas próprias cidades ou outras áreas, usando mais serviços para aumentar a produtividade, eficiência, habilidades de comunicação ou criar experiências que melhorem sua qualidade de vida.

O segundo ponto aborda a interconectividade como a principal evolução dos artefatos que nos rodeiam, quando estes passaram a combinar conectividade e consciência contextual em tempo real. Para este 
mesmo autor,

Ao invés de confiar em dados estáticos ou desatualizados, as redes de sensores nos permitem coletar estatísticas precisas sobre toda uma gama de variáveis que podem afetar a qualidade de vida urbana e, como conseqüência, fazer agir sobre essas variáveis. À medida que mais tecnologias ganham o potencial de se interconectar, no entanto, também precisamos estar cada vez mais conscientes das pegadas digitais e das trilhas de dados que deixamos para trás ao usá-las (WALRAVENS, 2015, p.282).

O terceiro e último ponto indica que, desde 2008 mais de metade da população mundial passou a viver em cidades. Walravens (2015) observa que o setor de tecnologias móveis de comunicação e informação está atento a este crescente deslocamento de pessoas para as áreas urbanas, e estão interessados naturalmente em oferecer serviços adaptados à vida na cidade. Segundo este autor as cidades e governos locais exploram as facilidades proporcionadas pelo avanço da tecnologia para proporcionar uma melhor qualidade de vida as seus cidadãos. Sobre isso, Walravens (2015, p.283) diz que, nos últimos anos, "essa questão foi capturada pelo conceito 'Smart City'. Este conceito tornou-se chave na ponte entre a pesquisa, projetos e iniciativas que exploram o papel da tecnologia na vida urbana".

Percebe-se, então, que a introdução de práticas e instrumentos tecnológicos vem modificando a rea- lidade de vida nas metrópoles, uma vez que equipes de projetistas, arquitetos, designers e outros profissionais das áreas criativas passam a contar com o reforço dos desenvolvedores de aplicativos móveis para a construção de uma cidade mais acessível. É a partir desta recente área do conhecimento que vem sendo inseridas novas dinâmicas no contexto da metrópole comunicacional.

É possível, então, notar que o smartphone é - neste momento - o artefato predominante como interface de contato entre o cidadão conectado e os serviços oferecidos na cidade. Esta relação é mediada através dos apps disponíveis nestes dispositivos, como uma camada entre a localização física do usuário e a informação virtual e social que pode ser ligada a ela (WALRAVENS, 2015).

A criação de apps que se relacionam com o espaço urbano e, consequentemente, trazem facilidades para a sociedade, acabaram alterando rotinas antigas e criando novos hábitos. Controlar o dia a dia a partir de um smartphone é uma realidade que já atinge mais de $16 \%$ da população mundial e que chegará a aproximadamente $50 \%$ no ano 2018 , segundo dados da empresa Ericsson (2012). Historicamente, sabe-se que os Estados Unidos alcançaram sozinhos no ano de 2012 a média prevista para o ano de 2018 no mundo. Por esse motivo, entender a metrópole comunicacional na atualidade, observando a introdução e impacto destas tecnologias, torna-se fundamental. 
Pelo caminho percorrido, constata-se então que vivemos um momento especial de efervescência projetual da metrópole comunicacional, principalmente dentro deste grupo de desenvolvedores de apps que vem alterando a realidade urbana com suas invenções e inovações a partir das tecnologias digitais. Neste sentido, é possível identificar a existência de dois grandes movimentos que pautam a criação de apps para a cidade: top-down e bottom-up. Apps top-down podem ser caracterizados como sendo aqueles elaborados pela governança da cidade e oferecidos para seus cidadãos. Esta categoria de app objetiva proporcionar facilidades e acesso a serviços da cidade, antes burocratizados ou inacessíveis. É o esforço voltado para o emprego inteligente de recursos e tecnologias que qualificam o território, viabilizando a cidade enquanto Smart City.

Já os apps bottom-up representam a manifestação da sociedade diante dos problemas da cidade, em que o próprio cidadão toma a iniciativa de propor uma solução amparada pelo plano digital. É o conceito de Smart Citizen, "aqueles que vivem, trabaIham e se envolvem em todo o tipo de atividades na cidade" (WALRAVENS, 2015, p.284). Os resultados de suas intervenções são esperados diante do que Meroni (2007) vê na formação de comunidades criativas: pessoas que cooperam na viabilização de soluções para seus problemas, buscando uma nova e sustentável maneira de se viver.
Se entendermos a metrópole comunicacional como uma grande plataforma de mediação para a discussão da cidade, pouco importa a direção do movimento que propõe sua qualificação, se top-down ou bottom-up. Assim como também é pouco relevante a natureza desta qualificação: se contempla problemas de infraestrutura urbana ou se trata de intervenções artísticas, por exemplo. A responsabilidade compartilhada é, talvez, a grande resultante deste exercício constante de apropriação da cidade.

São muitos os apps que interagem com as práticas relacionadas a territórios, sob seus mais diversos aspectos. No intuito de descobri-los, fez-se necessário acessar um dos principais canais de distribuição e comercialização de aplicativos móveis do mercado atual, a App Store, da Apple Inc.

Tal busca assumiu como método as premissas de Canevacci (1993), que defende a necessidade de querer perder-se e ter prazer nisso, aceitando ser estrangeiro, desenraizado e isolado. Por esse entendimento, partiu-se introduzindo no sistema de buscas da App Store palavras-chave mais amplas como: cidade, metrópole, urbano/urbe e lugares, além de internacionalizar tais termos testando-os em outros idiomas para também incluir nesta pesquisa suas traduções city, metropolis, urban, place, ciudad e cittá. Como resultado foram disponibilizados milhares de opções de apps, o que acabou por induzir a um maior aprofundamento no instrumento, 
agora considerando nova busca pelo quesito metrópoles. Assim, executou-se buscas pelo nome das dez metrópoles brasileiras mais populosas, bem como incluiu-se outras dez metrópoles que são referências mundiais. Percebeu-se necessário também observar alguns temas extraídos do cotidiano de quem vive nestes centros, como, por exemplo: serviços de mobilidade; alimentação; hospedagem; turismo; saúde; segurança; entre outros que foram derivados durante o processo.

As buscas feitas a partir de quatro dezenas de tópicos pesquisados retornaram um número aproximado de 45 mil opções de apps desenvolvidos sobre questões focadas na metrópole. Devido à impossibilidade de acessar todos eles, foi feita a seleção de alguns apps para perder-se, ou melhor, para observar, tendo como critério de escolha os aspectos de criatividade e inovação que tão bem caracterizam e potencializam a atuação dos autores destes apps. Despertaram atenção aqueles que propunham uma solução projetual que interagisse de forma inusitada - criativamente - com as dinâmicas da metrópole, algo que fosse inesperado, desconhecido por certo, que ajudasse a desvendar o potencial projetual, criativo e tecnológico em propor alternativas aos problemas urbanos.

Dentre as inúmeras opções retornadas, o primeiro app relevante desta pesquisa foi o Let'sPark, um app colaborativo para encontrar estacionamentos em qualquer cidade do Brasil. Deixando-se levar pela curiosidade, chegou-se ao app Nightmap, um tipo de mapeamento da noite local, que traz um mapa em que os usuários podem encontrar, avaliar ou adicionar locais de diversão como motéis, clubes de swing, casas de massagem, saunas, festas GLS, entre outros serviços para um público adulto. Testando outras frentes, descobriu-se o app B.O.Coleti$v o$, que diferente dos anteriores, serve mais para $f u$ gir de determinados locais do que para encontrar algum estabelecimento específico. Neste app específico, é possível registrar ocorrências de crimes (como furtos, assaltos, sequestros, etc) em um mapa coletivo com outros usuários, e também consultar outras ocorrências nas regiões desejadas.

Atualmente, a criação de apps com foco nas questões urbanas vem recebendo muitos incentivos por parte de instituições e governos. Foram detectados alguns exemplos de eventos explorando esta temática, como o NYC Big Apps 3.0, o Lisbon Big Apps e o Rio Apps, que desafiam as mentes criativas a tornarem as cidades melhores por intermédio das tecnologias móveis de comunicação. Neste contexto, merece destaque o concurso internacional AppMyCity, promovido pela New Cities Foundation, que premia aplicativos móveis que apresentem soluções para os percalços da vida na cidade, sendo o principal critério de participação a obrigatoriedade de estarem centrados nas questões urbanas, como mobilidade, gestão, saúde, água, igualdade, varejo, cidadania, arte e entretenimento. O vencedor da última edição foi o app colab.re $e^{6}$ que recebeu o título de 
7. Em março de 2014, a prefeitura de Curitiba/PR formalizou uma parceria com esta plataforma, lançando mais um canal de interação com a população e defendendo que o projeto-piloto faz parte de um plano do município para transformar Curitiba numa cidade cada vez mais digitalizada e cidadã.

8. É necessária uma ressalva sobre o uso do termo 'soluções' neste momento, já que ele se apresenta impreciso por não constatarmos uma eliminação plena dos problemas urbanos abordados através dos apps, o que configuraria 'uma solução', e sim um diálogo com tais demandas, uma espécie de negociação constante que insere novos elementos que aprimoram esta experiência tão intensa de viver continuamente a metrópole comunicacional e suas imperfeições.
Melhor App Urbano do Mundo. Trata-se de uma rede social colaborativa que incentiva a melhoria das cidades brasileiras sobre três aspectos: fiscalizar, propor e avaliar, sendo que todo conteúdo postado no app é enviado para as prefeituras ${ }^{7}$ cadastradas permitindo uma agilidade maior dos gestores.

Se a metrópole comunicacional de Canevacci era observada nas ruas, esquinas e em edificações, é possível perceber que nos dias de hoje há uma transformação em andamento. Temos sinais claros de que uma nova paisagem vem se constituindo, principalmente quando encontramos fragmentos de uma metrópole cada vez mais presente e frequente nas telas dos dispositivos móveis, em especial no conjunto de apps urbanos, constituindo assim a concepção da metrópole comunicacional 3.0 interpretada neste artigo. É notório que o conjunto de opções de apps para interagir com a metrópole comunicacional é extenso, diversificado e em número crescente, mas o mais instigante está na configuração deste momento atual, que traz consigo uma atmosfera criativa, coletiva e colaborativa, pensando, projetando e propondo soluções ${ }^{8}$ digitais para as questões do território, sempre tendo o software como mediador e agente integrador.

É neste cenário de valorização da classe criativa que o território se impõe como pauta para muitas reflexões, cabendo recordar que o recorte feito aqui se situa na denominada 'era da informação' e é permeado por um processo de 'smartphonização' da sociedade contemporânea. Este processo leva em consideração os dispositivos móveis como instrumento de 'comunicação' e meio transformador de determinadas práticas recorrentemente exercidas nas metrópoles. Destaca-se o termo comunicação, pois todos os apps compilados para enriquecer esta pesquisa têm em comum os processos midiáticos que carregam em si, já que faz parte de sua constituição conduzir a informação, que, neste contexto, é armazenada, compartilhada e atualizada constantemente pelos meios digitais.

\section{Considerações Finais}

Ao tecer as amarrações finais, é preciso lembrar que a visão apresentada derivou de um movimento compartilhado na introdução deste artigo, e que se consolidou especialmente na constituição da tríade entre o conceito de metrópole comunicacional, o atributo de cidade softwarizada e o suporte dos aplicativos móveis. A principal intenção foi tensionar a concepção de uma 'nova' metrópole comunicacional atualizada aos dias de hoje e seus processos midiáticos, que se veem cada vez mais impactados pelos recursos das tecnologias digitais, móveis e locativas, além das mutações que estas ocasionam no cotidiano deste espaço urbano.

Ao referenciar três momentos da citada metrópole comunicacional, identificados como 1.0, 2.0 e 3.0, 
buscou-se acompanhar a transformação do conceito apresentado por Canevacci, no ano de 1993, que aos poucos foi vendo diminuir sua existência original nas paisagens urbanas construídas e tornando-se cada vez mais presente e acessada nos ambientes virtuais, digitais e online de equipamentos eletrônicos.

Da metrópole 1.0, baseada na cidade pós-industrial da década de 1970 estruturada no consumo e comunicação, passando por sua versão 2.0 , reconhecida como evolução decorrente da sobreposição da camada de infraestrutura tecnológica, foi dando origem ao conceito de metrópole comunicacional 3.0 que percebemos a força e amplitude alcançadas pelo coro de vozes imaginado por Canevacci, presentes em todo lugar, e ainda maior, graças ao meio virtual.

Por outro lado, se o avanço possibilitado pela mobilidade e virtualidade começa a dissolver barreiras físicas e tecnológicas presentes no contexto urbano, indaga-se agora sobre quais seriam seus limites. As atuais tendências de consumo apontam para a superação dos smartphones até o ano de 2020 (ERICSSON, 2015). De acordo com recente pesquisa encomendada pela Ericsson (2015), a evolução tecnológica avançará com tal velocidade que substituiremos a tela do smartphone por assistentes pessoais de inteligência artificial, possivelmente acessados a partir de dispositivos tecnológicos de vestir. É o que aparelhos como AppleWat- ch, lançado em 2015, já começam a sugerir. Este movimento sugere que a relação do usuário com a metrópole passará a se dar intermediada pela inteligência artificial, prenunciando, o surgimento da Metrópole 4.0. 


\section{Referências}

ABINEE, Associação Brasileira da Indústria Elétrica e Eletrônica, 2013. Disponível em http:// www.abinee.org.br/

BARBERO, J. Martín., La Ciudad Virtual. Transformaciones de la sensibilidad y nuevos escenarios de comunicación., in Revista de la Universidad del Valle., n. 14, agosto de 1996, Cali., pp. 26-38.

BENEVOLO, Leonardo. História da Cidade. $5^{\mathrm{a}}$ ed. Editora: Perspectiva, 2012.

BLUMENFELD, Hans. A metrópole moderna. In: Cidades: a urbanização da humanidade. $2^{\mathrm{a}}$ ed. Trad. José Reznik. Rio de Janeiro: Zahar, 1972.

CANEVACCI, Massimo. A cidade Polifônica. Ensaio sobre a antropologia da comunicação urbana. Coleção Cidade Aberta. Ed. Studio Noel, 1993.

CRAPANZANO, Vincent. Hermes' Dilemma and Hamlet's Desire: Essays on the Epistemology of Interpretation. Cambridge, MA: Harvard UP, 1986.

DUBOIS, Philippe. Cinema, vídeo, Godard. São Paulo: Cosac Naify, 2004.
ESTEVES, João Pissarra. Ética da Comunicação

e dos Media Modernos - Legitimidade e poder nas sociedades complexas, Lisboa, Gulbenkian/JNICT, 1998.

ERICSSON. Ericsson Mobility Repport. Novem-

ber, Sweden: 2012. Disponível em <http://www.ericsson.com/> Acesso em 25 de abril de 2017.

ERICSSON. 10 Hot Consumer Trends 2016. Ericsson Consumer Insight SummaryMobility Repport. Dezembro. Sweden: 2015. Disponível em <http:// www.ericsson.com/> Acesso em 25 de abril de 2017.

FEATHERSTONE, Mike. Cultural theory and cultural change. London; Newbury Park: Sage Publications, 1992.

LEMOS, André. Cidade e mobilidade. Telefones celulares, funções pós-massivas e territórios informacionais. Revista Matrizes №. 1 Outubro, 2007.

MANOVICH, Lev. Software Takes Command. San Diego, 2008.

MCLUHAN, Marshall. McLuhan por McLuhan. Rio de Janeiro: Ediouro, 2005.

MERONI, Anna. Creative communities: people in venting sustainable ways of living. Milão: Polidesign, 2007. 
PARENTE, André. O virtual e o hipertextual. Rio de Janeiro: Pazulin, 1999.

PELLANDA, Eduardo Campos. A conexão entre lugares e espaços proporcionada pela rede Foursquare. Intexto, Porto Alegre: UFRGS, v. 1, n. 24, p. 164-175, janeiro/junho 2011.

PELLANDA, Eduardo Campos. A conexão entre lugares e espaços proporcionada pela rede Foursquare. Intexto, Porto Alegre: UFRGS, v. 1, n. 24, p. 164-175, janeiro/junho 2011.

SANTAELLA, Lúcia. Linguagens líquidas na era da mobilidade. SP: Paulus, 2007.
SMITH, Andy Hudson - Digital Urban - The Visual City. UCL Centre for Advanced Spatial Analysis. Working Papers Series - Paper 124 - Sept, 2007.

SOUZA, Marcelo Lopes de. ABC do desenvolvimento urbano. 2. ed. Rio de Janeiro: Bertrand Brasil, 2005. pp. 32-36, 55.

WALRAVENS, Nils. Mobile city applications for Brussels citizens: Smart city trends, challenges and a reality check. Telematics and informatics. n.32. p.282-299. 2015 